\title{
Natural Convection Heat Transfer from Vibrated Vertical Flat plate.
}

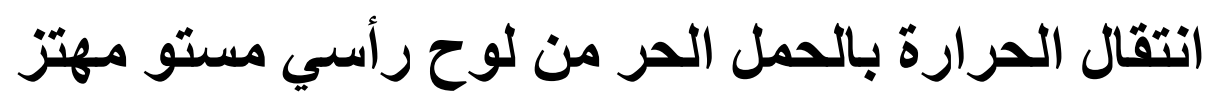

\author{
H. B. Al sultan, Ahmed A. Sultan* and H.R. El-Tahan** \\ *Department of Mechanical Power Engineering, Mansoura University, \\ Mansoura, EGYPT Corresponding author, Fax: +202 50-2244690 \\ E-mail: aasultan@mans.edu.eg \\ ** Department of Mechanical Power Engineering., Faculty of Engineering, \\ Fayoum University, Fayoum, Egypt
}

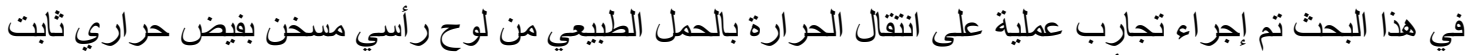

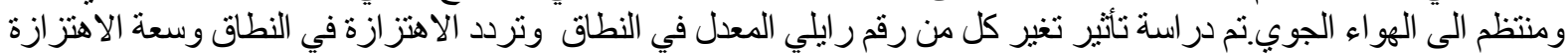

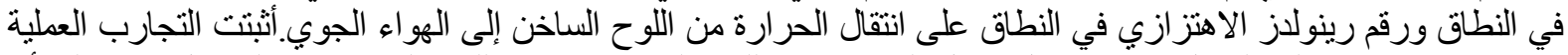

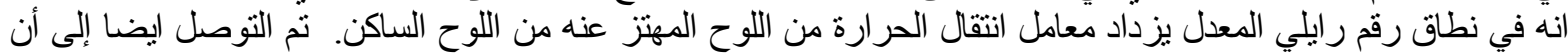

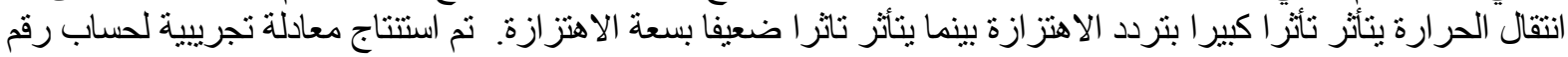

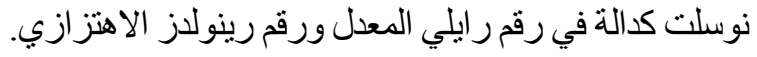

\begin{abstract}
Experiments were performed on natural convection heat transfer from vibrated vertical flat plate heated under constant heat flux. The working fluid used is air. The effects of modified Rayleigh number, $\left(10^{7} \leq \mathrm{Ra}^{*} \leq 10^{10}\right)$, the vibration frequency $(0 \leq \mathrm{F} \leq 25)$, and the amplitude $(0 \leq \mathrm{A} \leq 7.6 \mathrm{~mm})$, vibrational Reynolds number of $10^{2} \leq \operatorname{Rev} \leq 8^{*} 10^{4}$, were studied. Over the tested range of modified Rayleigh number, it is found that the vibrated plate generally shows higher heat transfer coefficients than that of the stationary one for all values of amplitude, and frequency. It is also concluded that the heat transfer is strongly affected by the vibration frequency while it is weakly affected by the vibration amplitude. The Nusselt number has been correlated in a dimensionless form as a function of modified Raylegh number, and Vibrational Reynolds number.
\end{abstract}

\begin{tabular}{|c|c|}
\hline Nomenclature & Greek symbols \\
\hline A Vibration amplitude, $\mathrm{m}$ & $\beta \quad$ Coefficient of thermal expansion of air, \\
\hline As Plate surface area, $\mathrm{m}^{2}$ & $\mathrm{~K}^{-1}$ \\
\hline $\mathrm{Cp}$ Heat capacity, KJ/kg.K & $\mathrm{r}$ Air density, $\mathrm{Kg} / \mathrm{m}^{3}$ \\
\hline F Vibration frequency, Cycle/s & Y Kinematic viscosity $\mathrm{m}^{2} / \mathrm{s}$ \\
\hline $\mathrm{g} \quad$ Gravity acceleration, $\mathrm{m} / \mathrm{s}^{2}$ & \\
\hline Heat transfer coefficient, $\mathrm{W} / \mathrm{m}^{2} \cdot \mathrm{K}$ & Subscripts \\
\hline $\mathrm{k}$ Thermal conductivity, W/m.K & cond conduction \\
\hline L Heated plate height, $\mathrm{m}$ & conv convection \\
\hline Motor revolution per minute & rad radiation \\
\hline $\mathrm{Nu}$ Average Nusselt number, & $\mathrm{w}$ wall \\
\hline Electric power, $\mathrm{W}$ & $\infty \quad$ ambient air \\
\hline Heat flux, W & \\
\hline q Heat flux density, $\mathrm{W} / \mathrm{m}^{2}$ & \\
\hline Ra* Modified Rayleigh number, & \\
\hline Rev Vibrational Reynolds number, & \\
\hline Ra* Modified Rayleigh number, & \\
\hline Rev Vibrational Reynolds number, & \\
\hline temperature, ${ }^{\mathrm{O}} \mathrm{C}$ & \\
\hline
\end{tabular}




\section{Introduction}

Free convection is actually conduction with subsequent fluid movement caused by changes in fluid density. Movement of the fluid takes place in a relatively narrow region known as the boundary layer. Most techniques designed to improve convective heat transfer have as their objective reducing the thickness of the boundary layer or increasing the transverse fluid motion in the boundary layer. Vibration is one method of increasing the heat transfer rate by additional fluid motion.

Vibration can be looked upon as a powerful tool for heat transfer enhancement. Neely (1964) studied the effect of diameter, temperature difference, and vibration intensity on the free convective heat transfer rate from horizontal cylinders subjected to transverse vibrations in air. The cylinders were vibrated over a frequency range of 0 to 88 cycles per second and an amplitude range of ( 0 to 8.7$) \mathrm{mm}$. The surface temperature of the cylinders ranged from (58.88 to 93.9) ${ }^{\circ} \mathrm{C}$, degrees Fahrenheit, and the maximum vibration intensity was 29 inches per second. Above vibration intensities of 12 inch per second, the variation of the heat transfer rate for both cylinders followed the forced convection curve recommended by Mc Adams (1954). Watson and Major (1965) investigated the effect of sinusoidal vibration in a vertical plane on the heat transfer rate from a cylinder in free convection in air. Three different cylinders with diameters $1.8 \mathrm{~mm}$, $3 \mathrm{~mm}$, and $6.4 \mathrm{~mm}$ were vibrated at amplitudes from 0 to $38.1 \mathrm{~mm}$, at frequencies from 16 to $80 \mathrm{cps}$, and surface temperatures of $37.8{ }^{\circ} \mathrm{C}$ and $93.4{ }^{\circ} \mathrm{C}$ above with diameters above room temperature. The heat transfer rate changed from that obtained in a free convection process to that obtained in a forced convection process at the conventional forced convection curve of McAdams (1954). Shokouhmand et al (2011) studied numerically the effect of the horizontal vibrations on natural heat transfer from an isothermal array of cylinders in air. Fluid flow and heat transfer characteristics were examined in the domain of the Rayleigh number, cylinders spacing, amplitude and frequency of oscillations such that: $10^{3}<$ $\mathrm{Ra}<10^{5}, 2<\mathrm{s} / \mathrm{d}<4,0.5<1<2$, and $0.1<$ $\mathrm{f}<0.4$. The obtained results revealed that increment of Rayleigh number and cylinders' spacing augmented the average Nusselt of each cylinder as well as higher oscillation amplitude and frequency.

Numerous works on thermovibrational convection focused on stabilizing or estabilizing effects of vibration on convective flows and/ or heat transfer enhancement due to vibration. Shrifulin (1986) investigated the effects of vibration on heat transfer enhancement and flow properties. Ivanova and Kozlov (1988) conducted an experimental study of heat transfer enhancement between two coaxial cylinders under vibration. Forhes et al (1970) carried out a similar experimental study on a liquid-filled rectangular cavity and noted a marked increase in the heat transfer rate by vibration.

Fu and Shich (1992) studied the heat transfer rate for the classical 2D square cavity problem. Frank (1996) completed a study of thermo-vibrational convection in a vertical cylindrical cavity for various values of Rayleigh number and the vibrational Grashof number. Results indicated that vibrational convection greatly increases heat transfer rate over the unmodulated case. Kimoto and Ishida (2000) examined the behavior of vibrational thermal convection in a square enclosure and effects on the average heat transfer characteristics of the natural convection field in it. In the computation, the Prandtl number, Rayleigh number, and vibrational Grashof number were held constant at $0.71,10^{4}$, and $10^{6}$, respectively. The angular frequency of vibration was changed in the range between 10 and 7680 . Kim et al (2002) studied the Effects of mechanical vibration on Critical Heat Flux 
(CHF) in vertical heated annulus. The experiments for dynamic response of the heater section without vibration excitation were carried out at mass flux of $50 \mathrm{~kg} / \mathrm{m}^{2} / \mathrm{s}$ and $400 \mathrm{~kg} / \mathrm{m}^{2} / \mathrm{s}$. CHF experiments with and without mechanical vibration were performed at mass flux of $115 \mathrm{~kg} / \mathrm{m}^{2} / \mathrm{s}$ and $215 \mathrm{~kg} / \mathrm{m}^{2} / \mathrm{s}$.

Only very few results have been reported on free convection from vertical surfaces subjected to either transverse or longitudinal vibrations. Prasad and Ramanathan (1971) studied experimentally the effect of heat transfer of longitudinal harmonic oscillations on free convective heat transfer from an electrically heated vertical plate. The experiments had been performed for frequencies ranged from 10 to $20 \mathrm{cps}$ at an amplitude of $0.25 \mathrm{in}$. and temperature was varying from 100 to $200^{\circ} \mathrm{F}$. A maximum increase in heattransfer rate of 33 per cent has been recorded.

Sarhan (2013) studied experimentally the effect of forced vertical vibrations on natural convection heat transfer, by the use of longitudinally finned plate made from Aluminum with dimensions (100, 300 and $3 \mathrm{~mm})$. Fin length, fin thicknesses and fin height were fixed at $300 \mathrm{~mm}, 3 \mathrm{~mm}$ and 13 $\mathrm{mm}$ respectively. The frequency was varied at $(0,2,6,10$ and $16 \mathrm{~Hz})$ and the amplitude in the range of (1.63-7.16) $\mathrm{mm}$. The relation between the heat transfer coefficient and the amplitude of vibration was directly proportional with the inclination angles of $\left(0^{\circ}, 30^{\circ}, 60^{\circ}\right)$.

The effect of oscillations upon convective heat transfer has been investigated for flat plates, cylinders and wires; for varied orientation of the vibration vector relative to these surfaces; for different ranges of vibration parameters- the amplitude and frequency ; and for different surface heating conditions. The results of these investigations vary from large increases to none or even decreases in heat-transfer rate.
The general purpose of the present investigation is to determine the effect of Rayleigh number, vibrational Reynolds number and vibration intensity on the free convective heat transfer rate from the surface of vertical flat plate. The plate is heated under constant heat flux subjected to vertical vibrations .The amplitude of vibration is in the range $0 \leq \mathrm{A} \leq 7.6 \mathrm{~mm}$, vibration frequency in the range $\underline{0} \leq \underline{\mathrm{F}} \leq \underline{25}$ cycle/s, vibrational Reynolds number in the range $10^{2} \leq \operatorname{Rev} \leq 8 * 10^{4}$ and modified Rayleigh number in the range $10^{7} \leq \mathrm{Ra}^{*} \leq 10^{10}$.

\section{Experimental Test-Rig and Procedure}

A schematic diagram of the test-rig is shown in Fig. 1. It consists essentially of the heated plate assembly, the vibrating, and mechanism the measuring instruments and the supporting frame.

\subsection{The Heated Plate}

The heated plate, Fig. 2, 300mm length, $150 \mathrm{~mm}$ width and $5 \mathrm{~mm}$ thickness is made from two galvanized iron sheets (2) with $1 \mathrm{~mm}$ thickness. The diagonals of the back surface area of the two sheets (7, 8) are divided to seven imaginary equal distance, each $22 \mathrm{~mm}$ length. In the middle of each distance, a copper-constantan thermocouple (3) is fixed on the plates back surfaces using epoxy steal. Thus the average of fourteen local temperatures is obtained. These values can be taken to represent the top surface temperatures because of the use of the galvanized steel test plates in which the difference between the estimated top surface temperatures and the measured values are found to be, in general, less than $0.1^{\circ} \mathrm{C}$. The plate is heated electrically by means of the heater (5) which is consists of a nickel-chromium heating strips wounded around a threaded mica sheet (4), and sandwiched between two mica sheets (6). Each mica sheet has $296 \mathrm{~mm}$ length, $146 \mathrm{~mm}$ width and $0.5 \mathrm{~mm}$ thickness. The heater with its mica sheets is sandwiched between the two galvanized 
sheets and the five layers are assembled using epoxy steel around their edges and pressed for 24 hours. The excess epoxy is removed and the frame of the assembly is cleaned while the two outside surfaces of the galvanized sheets are thoroughly polished. The leading edge of the plate is rounded (9) to avoid disturbance, while the trailing edge is packed with Teflon holder (1), which is rounded in the direction of flow to avoid disturbance in the trailing edge and screwed from the top for the connection with the vibrating assembly.

\subsection{The vibrating mechanism}

The vibrating mechanism consists of Three main parts namely, frequency inverter, electric motor and vibrating mechanism.

The inverter LSIS, model SV004IC5$1 F_{-}$of $0.4 \mathrm{~kW}$ capacity, works on the twophase, $50 \mathrm{~Hz}, 220$ volt alternating current connected to the main supply via an on-off switch. The inverter is capable of changing the two-phase , 220 volt , $50 \mathrm{~Hz}$ to a threephase current 220 volt variable frequency from 0 to $60 \mathrm{~Hz}$ which enable the electric motor to run at variable speed of rotation from 0 to 3450 R.P.M. Inverter resolution is $0.01 \mathrm{~Hz}$, while the accuracy is 0.01 of maximum output frequency. The inverter is provided with internal switch to change the frequency and a digital indicator to indicate the value of the output frequency. The electric motor is a three phase one of 0.5 HP running at 3000 R.P.M. at a frequency of $50 \mathrm{~Hz}$.

The vibrating mechanism shown in Fig (3) is a slider crank chain mechanism consists of a hollow rod of inside diameter equal to the outside diameter of the motor shaft and fixed over it using two threaded bolts through two threaded holes in opposite directions. The end of the hollow rod is machined so as to create eccentricities equal to have the required amplitude. A number of six hollow rods are machined with different eccentricities to give frequency amplitudes of $0.76,1.42$, $3.11,4.8$, and $7.6 \mathrm{~mm}$. A connecting rod assembled with the eccentric part of the hollow rod through a ball bearing using threaded bolt in order to facilitate its oscillation during motor rotation. The other end of the connecting rod is bolted with a vertical rod of diameter $12 \mathrm{~mm}$ oscillating through a cupper sleeve in order to permit only a vertical oscillation of this rod. The other end of the oscillated rod is threaded and connected to a Teflon holder through its threaded hole. The Teflon holder has a thickness of $20 \mathrm{~mm}$ and a length of $80 \mathrm{~mm}$ in perpendicular direction to the direction of oscillation. The bottom end of the Teflon holder is machined to have a slot of $10 \mathrm{~mm}$ deep $5 \mathrm{~mm}$ thickness and provided with two $5 \mathrm{~mm}$ threaded holes from one side that used to fix the oscillated plate using two threaded bolts.

\subsection{Electrical and Measuring Equipment}

Electric current to the nickelchromium strip was drawn from 220 volt $50 \mathrm{HZ}$ mains through one (Variance) variable transformer as seen in Fig. (1), which allowed a large step-down in voltage. A.C. was chosen because of its ready availability, ease of control, and lack of effect on the potentiometer. The current then passed through a switch and across the nickel-chromium strip. Insulated copper wire was used for the leads and was soldered to the nickel-chromium strip at points slightly inside the plate.

Current was measured with 0-3-15 ampere Weston Electric ammeter .Voltage was measured with a 0-15-150 volt Weston voltmeter. Voltage taps across the nickelchromium strip were soldered in together with the current taps at the same points, so that any voltage drop can be measured accurately.

The frequency of vibration is determined by a digital dial gauge model Mitutoyo ID-S1012M of measuring range of $0: 12.7 \mathrm{~mm}$ with a resolution of $0.01 \mathrm{~mm}$ and accuracy of $0.02 \mathrm{~mm}$. 


\subsection{Supporting Frame}

The frame for supporting the particular plate in use consists essentially of two wooden posts mounted vertically on a flat board as a base, and braced to insure rigidity. The baseboard was clamped firmly to the top of a desk and the entire setup, located in a small, interior, windowless room with a well-fitting door to avoid the effect of outside air current resulted from any movement outside the room. When this door is closed and the ventilating blower shut off no stray air currents were perceptible. Such elimination of stray air currents is of the utmost importance in natural convection studies.

\subsection{Experimental Procedures}

The plate is adjusted in its right vertical position and suspended in air far from any objects has an effect on the radiation and distortion of free convection current. The following procedures are carried out:

1. The surface of the plate is first polished from any impurities on the plate surface.

2. The amplitude is adjusted to a certain value using the right eccentric hollow rod

3. The frequency is adjusted using the inverter, to a predetermined value $\mathrm{w}$.

4. The transformer connected to the heater is adjusted at a certain desired value corresponding to the predetermined heat flux

5. The steady state is demonstrated by recording the reading of thermocouples every 10 minutes until the reading of these thermocouples remains nearly constant.

6. The following readings is recorded after reaching steady state conditions:

Ambient temperature ,T $\infty$, voltage drop across the heater, $\mathrm{V}$, current through the heater, I, thermocouples readings of the heated plate surface and surrounding air, motor frequency, F, using the RPM measuring device, and finally the amplitude of oscillation using the dial gage.

\subsection{Data reduction}

Applying the principle of conservation of energy gives:

$\mathrm{P}=\mathrm{Q}_{\text {cond }}+\mathrm{Q}_{\text {conv }}+\mathrm{Q}_{\mathrm{rad}}$

As the power leads, the thermocouples wires have very small cross section and the various connections of the apparatus are made of insulated materials, the amount of heat conducted away ( $\left.\mathrm{Q}_{\text {cond }}\right)$ through these members is very small and, therefore, can be neglected. The heat carried away by radiation $\left(\mathrm{Q}_{\mathrm{rad}}\right)$ is calculated through the course of this work and has a comparatively small value that can be neglected. On the other hand heat energy convicted away from the plate by convection through air ( $\left.Q_{\text {conv }}\right)$ can be expressed using Newton's law of cooling as follows:

$\mathrm{q}=\mathrm{P} / \mathrm{A}=\mathrm{h}\left(\mathrm{t}_{\mathrm{w}}-\mathrm{t}_{\infty}\right)$

Then the coefficient of natural convection heat transfer can be calculated from the following correlation:

$\mathrm{h}=\mathrm{P} /\left[\mathrm{As}\left(\mathrm{T}_{\mathrm{w}}-\mathrm{T}_{\infty}\right)\right]$

Average Nusselt number, $\mathrm{Nu}$ :

$\mathrm{Nu}=\mathrm{h} \mathrm{L} / \mathrm{k}$

Average modified Rayleigh number, $\mathrm{Ra}^{*}$ :

$\mathrm{Ra}^{*}=\mathrm{g}$ b r q Cp L ${ }^{4} /\left(\mathrm{k}^{2} \mathrm{n}\right)$

Vibrational Reynolds number, $\operatorname{Re}_{\mathrm{v}}$ :

$\mathrm{Re}_{\mathrm{v}}=\mathrm{A} \mathrm{F} \mathrm{L} / \mathrm{n}$

\section{Experimental Results and Discussion}

Two groups of results are given and discussed in this section. The first group of them is the results of heat transfer from stationary vertical heated flat plate under constant heat flux. The second group of results is the results of heat transfer from vertically vibrated heated vertical flat plate with vibration frequency $(\mathrm{F})$ ranges from 0 to 25 cycles per second (cps), and vibration amplitude (A) ranges from 0 to $7.6 \mathrm{~mm}$. 


\subsection{Results of stationary heated plate}

In order to check the validity of the experimental set up a comparison between the present results and the available published data is made. Fig. (4) indicates the relation between Nusselt number $(\mathrm{Nu})$ and modified Rayleigh number $\left(\mathrm{Ra}^{*}\right)$ for the present work and Sultan (1991). The figure shows that there is a good agreement between the two sets of results.

The present results of stationary heated vertical plate are used to be the reference of enhancement resulted from plate vibration. The correlation related $\mathrm{Nu}$ and $\mathrm{Ra}^{*}$ using curve fitting is suggested as:

$\mathrm{Nu}=0.76 \mathrm{Ra}^{*} 0.2$

With a maximum error of $\pm 10 \%$.

\subsection{Results of vibrated plate}

Experiments are carried out for frequency ranges from 0 to $25 \mathrm{cps}$, amplitude ranges from 0 to $7.6 \mathrm{~mm}$ (vibrational Reynolds number ranges from $2 * 10^{2}$ to $8 * 10^{4}$ ) and modified Rayleigh number ranges from $10^{9}$ to $1.5^{*} 10^{10}$. Figs. (5, 6 and 7$)$ indicate the relation between Nusselt number and modified Rayleigh number for vibration frequencies of 0,5 , 10, 16.7, 20 and 25 cps at amplitudes of $0.76,3.11$ and $6.7 \mathrm{~mm}$ respectively.

Fig (5) shows the effect of vibration frequency and modified Rayleigh number on Nusselt number at vibration amplitude of $0.76 \mathrm{~mm}$. It is shown from the figure that $\mathrm{Nu}$ increases with $\mathrm{Ra}^{*}$. It is also indicated that $\mathrm{Ra}^{*}$ has a significant effect on $\mathrm{Nu}$ especially for low values of vibration frequency. But this effect decreases as the value of vibration frequency increases. It can be concluded also that Nusselt number increases with vibration frequency up to a maxim value at frequency equal to $20 \mathrm{cps}$ and then decreases with further increase of vibration frequency. This is may be due to the boundary layer separation due to slips of air over the plate surface with the increase of frequency i.e. the increase of the relative velocity between air and plate surface.
Figs (6 and 7) indicate the relation between $\mathrm{Nu}$ and $\mathrm{Ra}^{*}$ for the same frequency range as in Fig. (5) but with vibration amplitudes of 3.11 and $7.6 \mathrm{~mm}$ respectively. It is seen from the two figures that the relation between $\mathrm{Nu}$ and both vibration frequency and $\mathrm{Ra}^{*}$ is the same as discussed in Fig. (5).

From the comparison between Figs 5, 6 and 7 one can recognize that $\mathrm{Nu}$ is weakly affected by vibration amplitude for the entire range of $\mathrm{Ra}^{*}$ values. Also the effect of vibration frequency on Nusselt number increases with increasing vibration amplitude.

\subsection{Suggested correlation}

An attempt is made to correlate the present experimental results in the form $\mathrm{Nu}$ $=\mathrm{f}\left(\mathrm{Ra}^{*}\right.$ and $\left.\mathrm{Re}_{\mathrm{v}}\right)$ using the statistics program SPSS Statistics 17.0 in the following form:

$\mathrm{Nu}=0.63 \mathrm{Ra}^{* 0.214}\left(1+0.00236 \operatorname{Re}_{\mathrm{v}}{ }^{0.31}\right)$

Figure (8) Shows the relation between Nusselt number calculated from the suggested equation, $\mathrm{Nu}_{\mathrm{c}}$, and the experimental one $(\mathrm{Nu})$. It is seen from the figure that the suggested equation predicts the Nusselt number values with an error of $\pm 8 \%$.

\section{Conclusions}

The present work concerns the effect of vibration characteristics, namely frequency and amplitude on Nusselt number of free convection from vertical flat plate heated under constant heat flux. Experiments has been worked under frequency ranges from 0 to $25 \mathrm{cps}$, amplitude ranges from 0 to $7.6 \mathrm{~mm}$ (i.e. vibrational Reynolds number ranges from $10^{2}$ to $8^{*} 10^{4}$ ) and modified Rayleigh number from $10^{9}$ to $1.5^{*} 10^{10}$. From the previous results the following conclusions are made:

1. Nusselt number increases with modified Rayleigh number and the rate of increase decreases with the increase of Rayleigh number. 
2. Frequency of vibration significantly increases the heat transfer rate especially at lower values of modified Rayleigh number.

3. The influence of the frequency of vibration increases with frequency amplitude.

4. The amplitude of vibration has weak effect on the increase of heat transfer rate at constant values of $\mathrm{Ra}^{*}$.

\section{References}

[1]. McAdams, W.H., (1954), "Heat Transmission", New York, McGrawHill Co., Inc. 1954.

[2]. David F. Neely, (1964),"Effect of Vibration on Heat Transfer From Cylinders in Free Convection", Thesis, Presented to the Faculty of the School of Engineering of the Air Force Institute of Technology, Air University, B.S. August.

[3]. William J. Watson,(1965), "Effect of Vibration on Heat Transfer from Cylinders Vibrated Sinusoidal within a Vertical Plane in Free Convection", Thesis Presented to the Faculty of the School of Engineering of the Air Force Institute of Technology, Air University.

[4]. Forbes R.E., Carkey C.T. and Bell C.J., (1970), "Vibration Effects on Convective Heat Transfer in Enclosures" J. Heat transfer No. 92, pp. 429-438.

[5]. Prasad K. Krishna and Ramanathan V., (1972), "Heat Transfer by Free Convection from a Longitudinally Vibrating Vertical Plate", Int. J. Heat Mass Transfer, vol. 15, pp. 12131223. Pergamon Press.

[6]. Shairfulin, A. N., (1986), "Super Critical Vibration Induced Thermal Convection In A Cylindrical Cavity" Fluid Mech. Sov. Res 15, pp. 28-35.

[7]. Ivanova, A. A. and Kozlou V. G., (1988), "Vibrationally Gtavitational Convection In A Horizontal Cylinderical Layer Heat Transfer" Sov., Res 20, pp. 235-247.
[8]. Sultan A. A., (1991), "Natural Convection Heat Transfer from a Uniform Heat Flux Plate with Arbitrary Inclination", Mansoura Engineering Journal (MEJ), Vol. 16, No. 2, June, PP. M98:M104.

[9]. Upenskii V. and Favier J. J., (1994), "High Frequency Vibration and Natural Convection In Bridgman-Scheme Crystal Growth" Int. J. Heat, Mass Transfer No.37, pp 691-698.

[10]. Ftank, T. F., (1996), "Thermovibrational Convection in a Vertical Cylinder" Int. J. Heat Mass transfer, vol. 39, No 14, pp 2895-2905.

[11]. Hideo Kimoto and Hideshi Ishida, (2000), "Vibration Effects on the Average Heat Transfer Characteristics of the Natural Convection Field in a Square Enclosure", Heat Transfer-Asian Research, 29 (7), 545-558.

[12]. Dae Hun Kim, Yong Ho Lee and Soon Heung Chang, (2002), "Effects of mechanical vibration on Critical Heat Flux in vertical annulus", Proceedings of the

[13]. Korean Nuclear Society Spring Meeting KwangJu, Korea, May.

[14]. Wu-Shung $\mathrm{Fu}$ and Chien-Ping Huang, (2006), "Effects of a Vibrational Heat Surface on Natural Convection in a Vertical Channel Flow", International Journal of Heat and Mass Transfer 49, 1340-1349.

[15]. Shokouhmand H., Noori Rahim Abadi S. M. A. and Jafari A., (2011), "The effect of the horizontal vibrations on natural heat transfer from an isothermal array of cylinders", Int J Mech Mater Des, 7:313-326.

[16]. Abdalhamid Rafea Sarhan (2013), "Vertical Forced Vibration Effect on Natural Convective Performance of Longitudinal Fin Heat Sinks", Tikrit Journal of Engineering Sciences/Vol.20/No.2/March, (60-69). 
1-Vibrating mechanism

2-Motor shaft

3- Electric motor

4-Connecting rod

5- Wooden frame

6-Transformer

7-Heated plate

8-Bench

9-Data logger

10-Computer

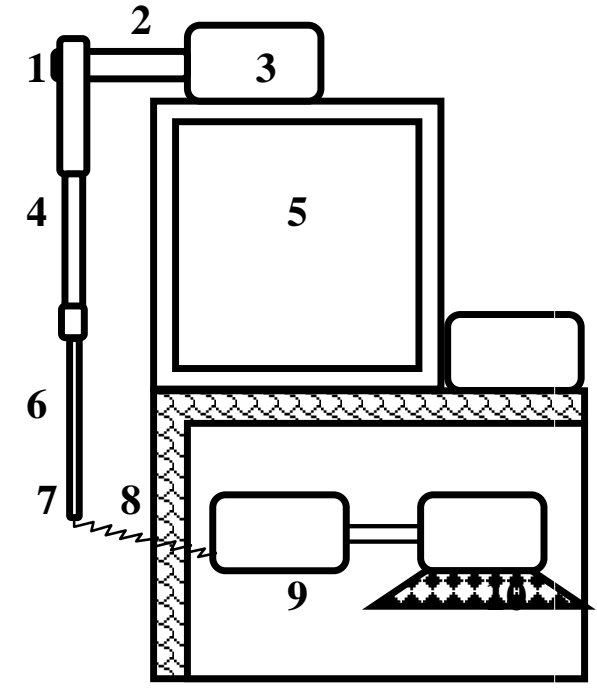

Fig. (1) Experimental test rig

1-Galvanized iron sheet 2-The rmocouples

3-Mica sheet

4-Electric heater

5-Mica sheet

6- Thermocouples right face distribution

7- Thermocouples left face distribution
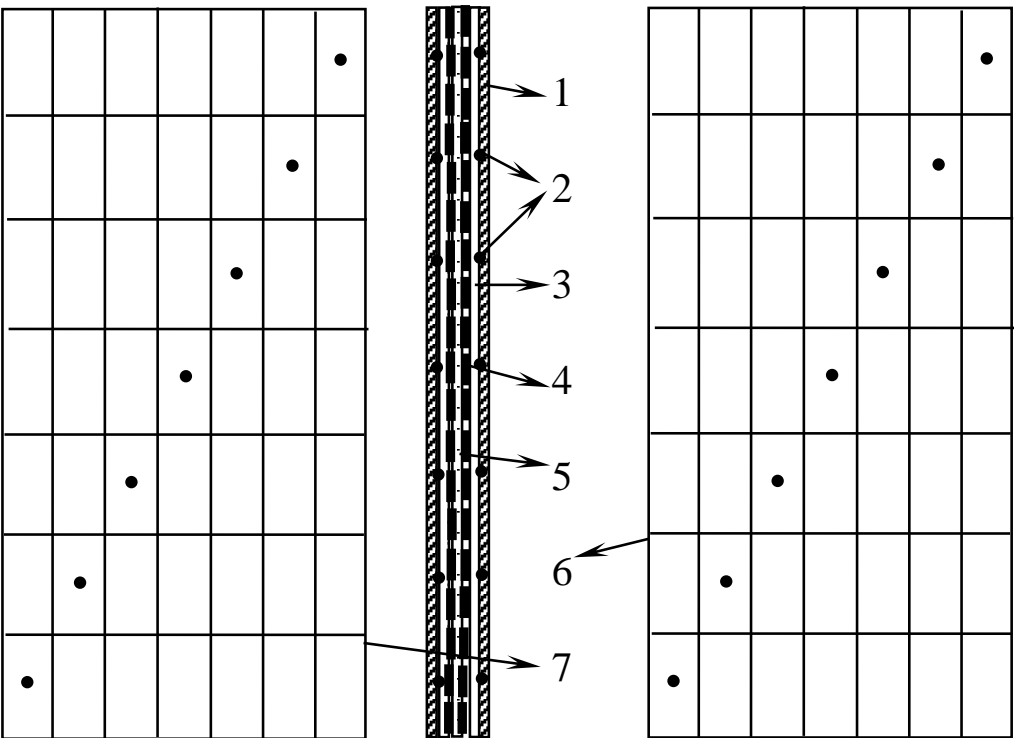

Fig. (2) The heated plate assembly 


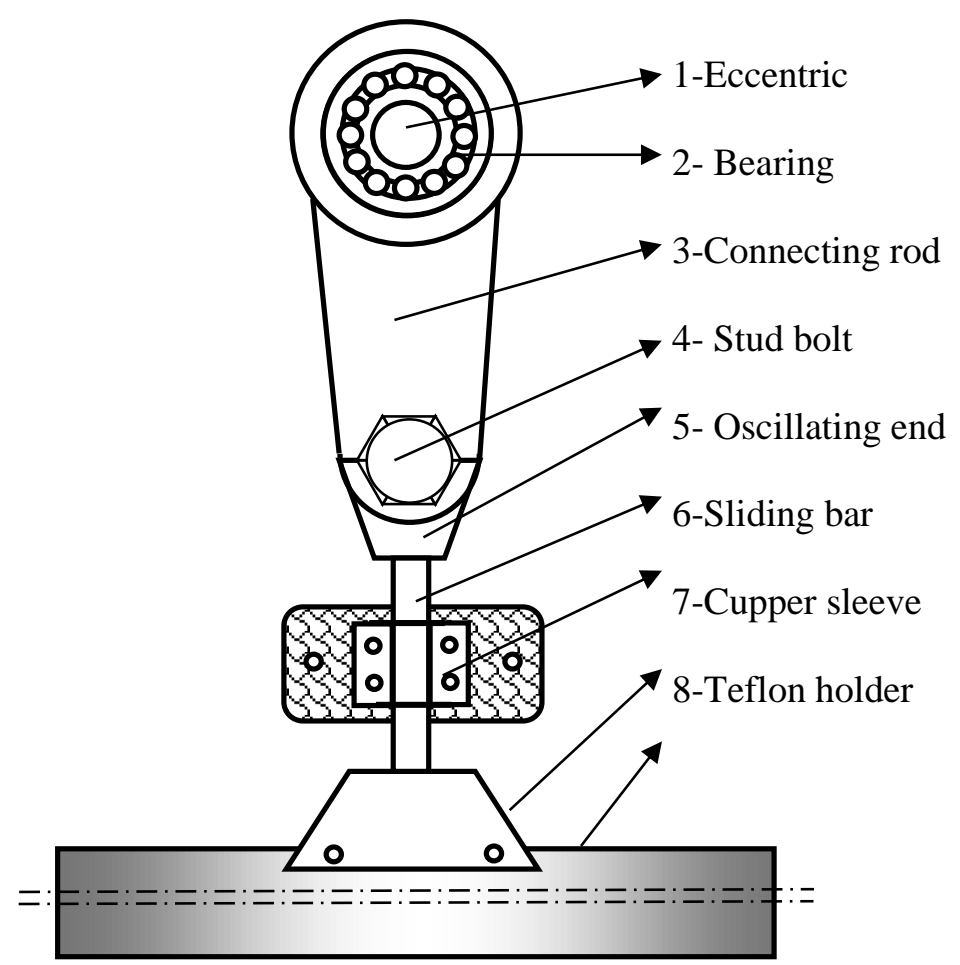

Fig.(3) Vibrating mechanism assembly
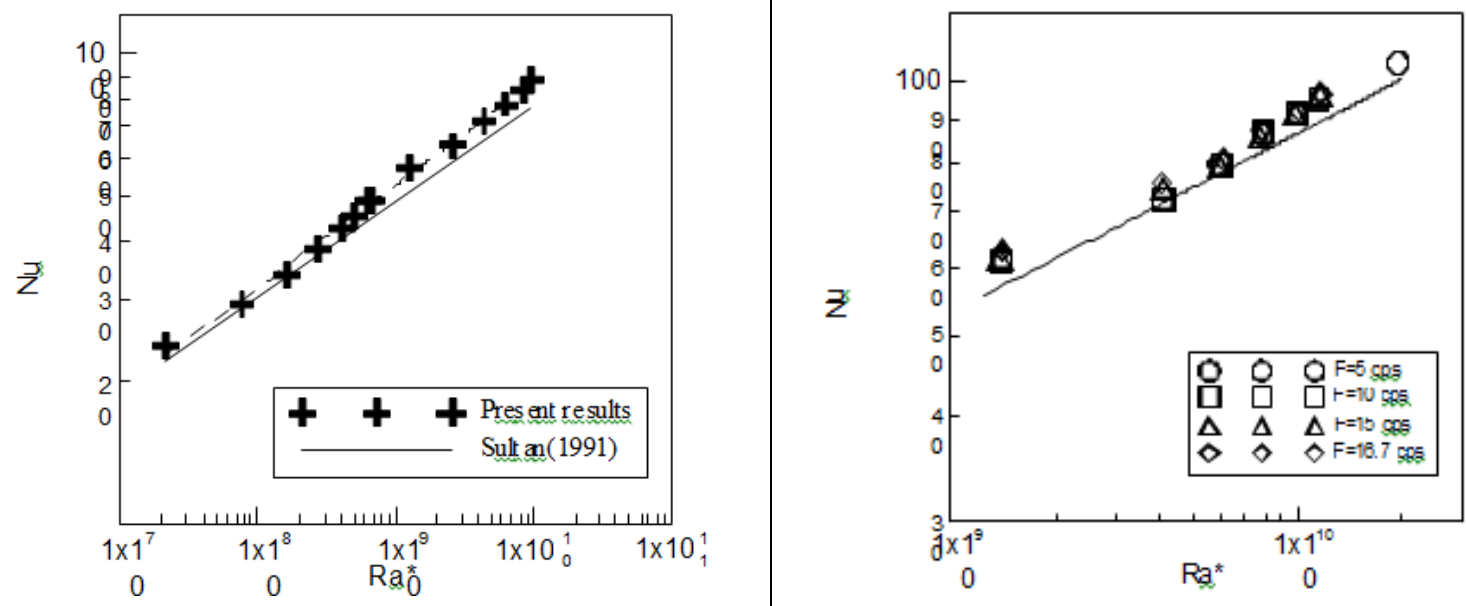

Fig. (4) Reltion between $\mathrm{Nu}$ and $\mathrm{Ra}$ * for present study and that of Sultan (1991) 

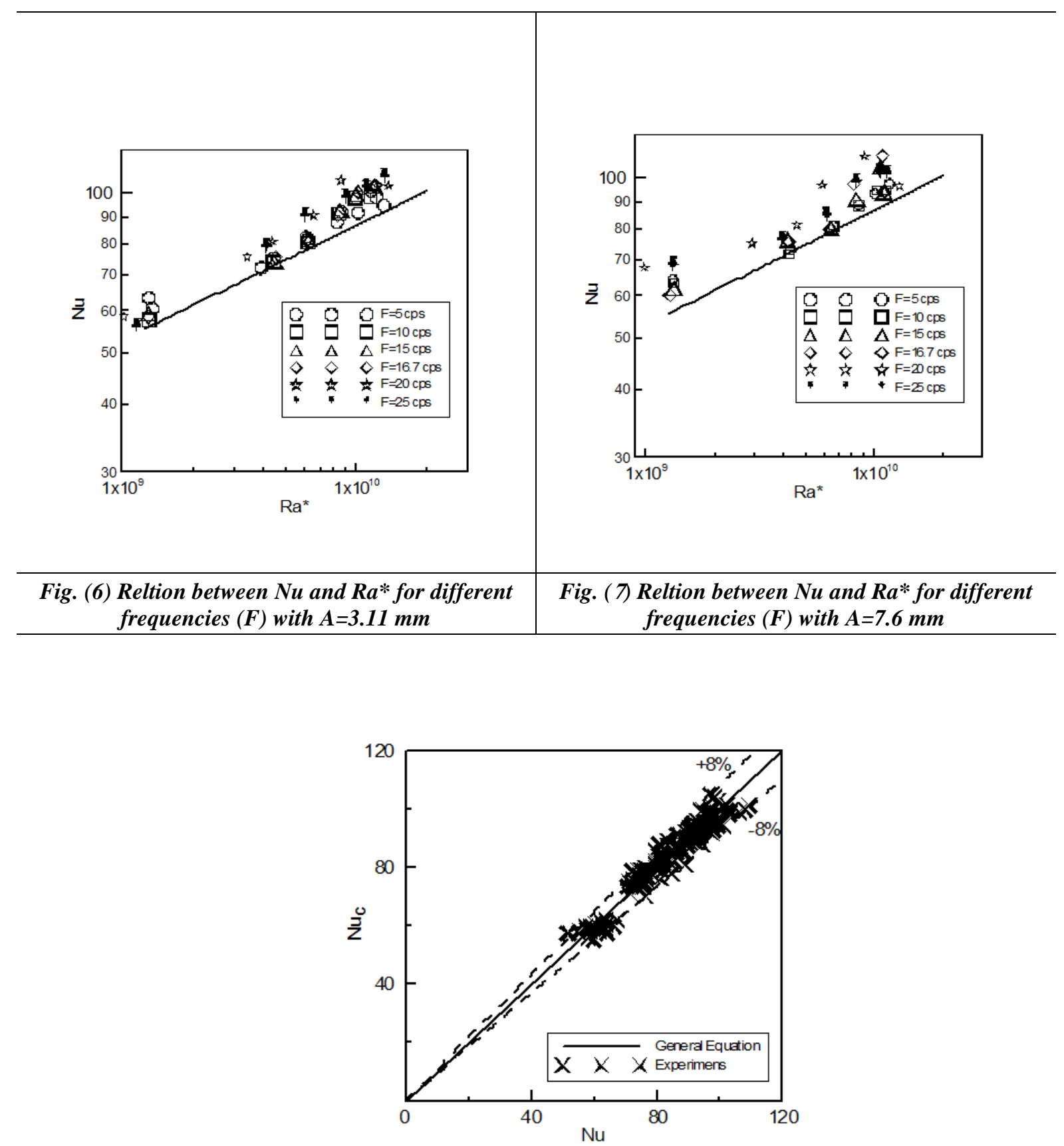